\title{
A reassessment of radiogenic and stable strontium isotope systematics in constraining silicate and carbonate weathering processes in mountain streams
}

\author{
Ni Su, Shouye Yang, Zhouyang Wu, Kai Deng, LeI \\ $\mathrm{BI}$
}

State Key Laboratory of Marine Geology, Tongji University, Shanghai 200092, China, nsu@tongji.edu.cn

Small mountainous rivers in Taiwan deliver disproportionately large quantities of suspended and dissolved solids to the global ocean due to extraordinarily high physical denudation rate and high chemical weathering rate in the world, often in response to catastrophic events such as earthquakes and tropical cyclones. The combined application of radiogenic and stable strontium isotopes $\left({ }^{87} \mathrm{Sr} /{ }^{86} \mathrm{Sr}\right.$ and $\left.\delta^{88 / 86} \mathrm{Sr}\right)$ are robust tracers for the source and mass-fractionation identification of $\mathrm{Sr}$ in rivers. We present ${ }^{87} \mathrm{Sr} /{ }^{86} \mathrm{Sr}$ and $\delta^{88 / 86} \mathrm{Sr}$ data of river water and spring water from two small mountain catchments with different geological types, Choshui and Liwu Rivers, in Taiwan Island. $\mathrm{Ca}^{2+}$ is the major cation in both rivers, especially for the Liwu River originating from terrains covered with marble in the downstream. The major ion chemistry and $\mathrm{Sr}$ isotopes show some variation along the river continuum, but the direction is inconsistent in both rivers. For spring water, the concentration of major cations and $\mathrm{Sr}$ isotope composition varied significantly as affected by rainfall.

The covariation exists between $\mathrm{Ca} / \mathrm{Na}$ vs. $\mathrm{Mg} / \mathrm{Na}$ and $\mathrm{Ca} / \mathrm{Na}$ vs. Sr/Na in the Choshui and Liwu Rivers, indicating mostly the mixing processes between carbonates and silicates. Further analysis of ${ }^{87} \mathrm{Sr} /{ }^{86} \mathrm{Sr}$ vs. $\mathrm{Ca} / \mathrm{Sr}$ and $\delta^{88 / 86} \mathrm{Sr}$ vs. Ca/ $\mathrm{Sr}$ ratios show strong positive correlations. This perfectly illustrates that the sources of the major ions and $\mathrm{Sr}$ in the Choshui and Liwu Rivers are a result of silicate and carbonate weathering. As a result, the ${ }^{87} \mathrm{Sr} /{ }^{86} \mathrm{Sr}$ and $\delta^{88 / 86} \mathrm{Sr}$ isotope compositions are also coupled from one another in both rivers and respond to the varying contribution from weathering of silicate and carbonate rocks. In a global-scale river, however, it appears the problem of the complex lithology, differential weathering pattern, physical erosion and seasonal variations of the drainage basins, which shows that ${ }^{87} \mathrm{Sr} /{ }^{86} \mathrm{Sr}$ may not be relevant to $\delta^{88 / 86} \mathrm{Sr}$. Nevertheless, further investigations on decoupled behavior of radiogenic and stable $\mathrm{Sr}$ isotope compositions are required to better understand of the its sources and isotope fractionation mechanisms in supergene environments and the global Sr cycle. 